\title{
Technology Adoption Strategies in the Supply Chain: The case of Vietnamese Young Small and Medium-sized Enterprises
}

\author{
Quang-Thanh Ngo ${ }^{1,2, * \mathbb{D}}$, Ngoc-Phuc Doan ${ }^{3}$, Thanh-Hai Thi Tran ${ }^{4}$ and Tien-Dung Nguyen ${ }^{2,5}$ \\ 1 Center for Economic and Financial Research, University of Economics and Law (UEL), \\ Ho Chi Minh City 71309, Vietnam \\ 2 University of Economics and Law (UEL), Vietnam National University Ho Chi Minh City (VNU-HCM), \\ Ho Chi Minh City 71309, Vietnam; ntdung@uel.edu.vn \\ 3 Faculty of Economics \& Law, University of Finance-Marketing, Ho Chi Minh City 72910, Vietnam; \\ doanphuc@ufm.edu.vn \\ 4 School of Accounting, University of Economics Ho Chi Minh City (UEH), Ho Chi Minh City 72407, Vietnam; \\ thanhhai@ueh.edu.vn \\ 5 Board of Rectors, University of Economics and Law (UEL), Ho Chi Minh City 71309, Vietnam \\ * Correspondence: thanhnq@uel.edu.vn
}

Received: 27 April 2020; Accepted: 14 May 2020; Published: 17 May 2020

check for updates

\begin{abstract}
The paper, using a three-wave unbalanced panel of 3252 observations of young small and medium-sized firms in 2011-2013, examines the effect of direct linkages between firms with foreign direct investment and young small and medium-sized firms on technology adoption strategies and the further influence of technology transfers from such linkages on technology adoption strategies. Moreover, the paper analyzes the extent that economic obstacles may cause young small and medium-sized firms to choose different adoptions. Our analysis shows that exporting firms do not tend to conduct embodied backward/forward adoptions, but more likely adopt the embodied backward purchasing. In addition, the impact of competitiveness follows an inverse U-shaped pattern for the embodied backward adoption, but a U-shaped pattern for the disembodied adoption. In terms of market power, there exists an inversed U-shaped pattern for the embodied backward adoption. Under the impact of foreign direct investment (FDI) linkages and vertical spillovers, it is found that technology transfer through backward/forward linkages is associated with the embodied ones, whereas a linkage with FDI domestic customers/suppliers is less likely associated with the embodied ones. In addition, under technology transfer, firms facing economic constraints may overcome these by looking for other financial sources and embodied technology transfer. The paper suggests the path for FDI firms, young small and medium-sized enterprises (SMEs), and technology adoption strategies in the future.
\end{abstract}

Keywords: technology adoption; embodied backward adoption; embodied backward purchasing; embodied forward adoption; embodied forward purchasing; disembodied adoption; supply chain; young small and medium-sized firms; Vietnam

\section{Introduction}

Small and medium-sized enterprises (SMEs) contribute development to both developed and developing countries (Organization for Economic Cooperation and Development [1], Filipe, et al. [2], de Kok, et al. [3], Luetkenhorst [4], Jamali, et al. [5]; United Nations Industrial Development Organization [6]). SMEs make up 95\% of companies in OECD member countries [1]. Accounting for 90\% of businesses globally and $50 \%$ to $60 \%$ of employment [4], SMEs play a significant role in job creation 
and poverty alleviation in developing countries [3,7]. SMEs also are portrayed in the literature as one of the important pillars of healthy economic growth and vitality, through their young entrepreneurial talent and innovation activities (Jamali, Lund-Thomsen and Jeppesen [5], United Nations Industrial Development Organization [6]). Among SMEs, recent development has paid much attention to the young SMEs. Czarnitzki and Delanote [7] argue further that young SMEs are interrelated in terms of such characteristics as size of operation (labor, capital) and duration of operation (age), and thus a new category for young SMEs has been formulated. Several studies have followed this new classification of firms (Schneider and Veugelers [8], Veugelers [9]).

Aghion and Howitt [10] further stress that young small firms are the main forces to cultivate new technologies, and thus increase productivity. Concerning innovation, SMEs are said to depend profoundly on outdoor innovation (Ortega-Argilés, et al. [11], Rammer, et al. [12]). In other words, SMEs prefer less costly and low-risk technology choices than formal in-house R\&D (Dahlander and Gann [13], Spithoven, et al. [14]). Although R\&D is widely recognized as the main components of innovation (Máñez, et al. [15], Audretsch, et al. [16], Tingvall and Poldahl [17]), R\&D investment likely faces uncertainty in success, is costly, and requires many endowment resources [16]. Therefore, instead of investing in R\&D, firms can enjoy a type of technology diffusion, namely the adaptation and/or adoption of available technologies in the world (Chang and Robin [18], Brandt and Zhu [19], Bartoloni and Baussola [20]). That is also the way that firms in developing countries may choose to improve their productivity by absorbing the existing technology suitable for them (Glass and Saggi [21], Basant and Fikkert [22], Wang and Blomström [23]). A study of Basant and Fikkert [22], for example, found that Indian firms' exploration of existing technologies obtain a higher return than innovative activities.

Foreign direct investment (FDI) often comes with spillovers. In general, there are two main spillover mechanisms as specified in Newman, et al. [24], and Zapkau, et al. [25]. Accordingly, horizontal spillovers come from transferring FDI firms' knowledge and technology to competing firms in the same sector, and vertical spillovers occur through the supply chain when foreign suppliers transfer to domestic producers [24]. There has been a huge amount of empirical literature of FDI spillovers (Caves [26], Rodriguez-Clare [27], Markusen and Venables [28], Blalock and Gertler [29], Smarzynska Javorcik [30], Kugler [31], Newman, Rand, Talbot and Tarp [24]). However, Smeets [32] concludes that although technology transfers and technology spillovers are interrelated concepts, they are distinct by nature, and this feature should be operationalized in the empirical analysis. Giroud, et al. [33] also criticize that the current literature focuses on external effects from FDI rather than on identifying the direct linkage effects between firms with foreign investment and domestic enterprises. Some attempts so far have been made to highlight the important technology linkages between two types of firms. The most recent study in this direction by Newman, Rand, Talbot and Tarp [24] finds that direct forward linkages from FDI suppliers to domestic firms are positively associated with productivity.

Until now, most micro-level studies of technology adoption are in the context of developed countries (Dunne [34], Cohen and Levin [35], Rose and Joskow [36]). Few notable exceptions in the context of developing countries are Brandt and Zhu [19], and Vishwasrao and Bosshardt [37]. Developing countries differ in their institutions and endowments from developed ones, and therefore we expect that technology adoption would also differ, especially by young SMEs. Yet not much is known empirically about what causes technology adoption by young small firms in developing countries. Specifically, the factors causing young small firms to become young adoption companies (YACs, those that have less than six years of operation, have employees from 10 to less than 250, and adopt) still remain unclear. In addition, empirical evidence so far is still mixed and this is a problem for effective support schemes. Moreover, financial constraints and socio-economic obstacles also hinder the absorption of technology transfer, especially in the context of Asian countries that have recovered from global financial and economic crises ([38], [39]). The current study goes further by examining the factors determining the probability of conducting different technology adoption strategies by YACs. Factors under examination include direct foreign-domestic linkages, technology transfers derived from such linkages, economic obstacles, and the interactions between them. 
Combining two datasets from Vietnam, namely the Vietnam Technology and Competitiveness Survey (TCS) and the Vietnam Enterprise Survey (VES) in 2011, 2012, and 2013, we construct a unique panel dataset of 3252 young SMEs to examine: (1) the extent to which direct foreign-domestic linkages lead to technology adoption strategies and (2) whether technology transfers derived from such linkages further explain technology adoption strategies. The paper then goes further to examine, under the influence of FDI linkages and technology transfers, (3) to what extent economic obstacles may cause young SMEs to choose different adoptions. To be more specific, the current article analyzes the direct linkage effects, and technology transfer between FDI firms and young SMEs, economic obstacles, and the interactions between them that causes young SMEs to conduct technology adoption strategies in the supply chain (existing through direct transfer of technology between linked firms), namely: embodied backward adoption (EBA), embodied backward purchasing (EBP), embodied forward adoption (EFA), embodied forward purchasing (EFP), and disembodied adoption (DIA). We employ a selection probit model to examine the issues. The main idea is that, in each particular market, firms conduct two decisions. First, they decide to adopt or not. Second, those firms that decide to adopt have to decide a particular technology adoption from a list of five choices.

The paper contributes to the literature of innovation, FDI, and young SMEs' behavior in several points. First, it is the first one to explore factors behind YACs' choices of technology adoptions in the context of developing countries. Second, it examines the concerning issues along the supply chain, and thus the vertical effects of technology transfers are captured in their multi-dimensions. Third, by distinguishing technology transfers from technology spillovers, their direct and indirect impacts are estimated.

The article is presented as follows. Section 2 presents the literature review. Section 3 is about data and methods. Section 4 exhibits empirical results and discussion. Section 5 delivers the main conclusions.

\section{Literature Review}

There are heterogeneous approaches concerning the determinants of the adoption decision of firms, namely: rank, stock, order, and epidemic models. The rank model, referring to the firm characteristics (e.g., the firm size), is critical to explaining firms' decision to adopt (Mansfield [40], David [41], Davies [42], Ireland and Stoneman [43]). The stock model derives from the assumption that expected profits from the use of new technology decreases as the number of previous adopters increases [44], while the order model implies that the firm's position in the adoption order determines its return from the adoption of the new technology, therefore causing competition to be first in the technological race [45]. The epidemic model stresses the role of information in the diffusion process [40], which is acquired through informal contacts between firms.

Within the framework of the above-mentioned models, plenty of work has been done so far. For rank theory, firm size with a positive effect (or the "Schumpeterian hypothesis") is found in studies of Faria, et al. [46], Arvanitis and Hollenstein [47], Karshenas and Stoneman [48], Bartoloni and Baussola [20], Chang and Robin [18], Kelley and Helper [49], and an "inverted-U" pattern in Chang and Robin [18]. Apart from firm size, other aspects of firm characteristics have been examined, such as workforce age (Meyer [50]), and location (Faria, Fenn and Bruce [46], Kelley and Helper [49], Antonelli and Gottardi [51]).

Many studies also distinguish the heterogeneity between domestic firms and foreign affiliates in the implementation of technology adoption. Wang and Blomström [23] study technology transfer activities by domestic and foreign firms and find that domestic firms invest in learning certain new technologies from the multinational companies until the domestic firms become more competitive, as more new technology would be transferred. The view that investment in learning or imitation by domestic firms spurs new technology transfer by multinational companies is also supported by Vishwasrao and Bosshardt [37]. 
In addition, Karpaty and Kneller [52] suggest that the smaller technology gap between domestic firms and the foreign affiliates is usually associated with the higher rate of technology transfer. Glass and Saggi [21] also found that shrinking the technology gap between FDI firms and domestic ones tends to improve the quality of technology transferred by FDI firms. These papers thus suggest that interaction between domestic and foreign-owned firms is an important aspect of the process of technology adoption.

Other empirical results contribute to the understanding of determinants of technology adoption. Blomström, et al. [53] found that technology purchasing and increased investment by domestic firms are significant determinants of technology transfer by multinationals. Vishwasrao and Bosshardt [37] found those firm characteristics, market structure, and competition for foreign technologies impact the technological adoption decisions of Indian firms and foreign subsidiaries. Chang and Robin [18], using a panel of 27,754 firms from 1992 to 1995 in twenty 2-digit Taiwanese industries, found that, in all industries, the intensity level of technology imports is highly associated with firm size, following an "inverted-U" relationship. Siddharthan and Safarian [54] used pooled data on Indian manufacturing firms and found that a firm's years of operation are positive in determining the import of capital goods without foreign equity participation and the purchase of technology from the market. However, Pandit and Siddharthan [55] found that the age of factories and machinery harmed technological opportunities in various Indian manufacturing industries for the same period. Siddharthan and Safarian [54] also found market share to be unimportant as a determinant of capital goods importing in the case of foreign affiliates in Indian chemical and other industries during 1987-1989.

Recent research development of FDI-related technology transfer evokes that FDI motivation is led by qualified labor and suitable labor costs, the host country's local market size, global supply chain involvement [39,56], and financial and economic constraints [38].

The overview of empirical studies so far suggests that much understanding of technology spillovers has been attained. However, as suggested by Smeets [32], and Giroud, Jindra and Marek [33], direct effects of linkages between firms with foreign investment and domestic enterprises need to be carefully examined, especially in the relationship with technology adoption strategies where empirical evidence is still so rare. On top of that, technology transfers derived from such linkages, economic obstacles, and the interactions between them also call for an investigation.

\section{Data and Methodology}

\subsection{Data}

The current study explores two data sources. The first data set was obtained from the Vietnam Technology and Competitiveness Survey (TCS), which was conducted in 2011, 2012, and 2013, by the Central Institute for Economic Management (CIEM), the General Statistics Office (GSO), and the Development Economics Research Group (DERG) of the Department of Economics, University of Copenhagen (CIEM and University of Copenhagen [56], CIEM and University of Copenhagen [57], CIEM and University of Copenhagen [58]). The TCS questionnaire asks firms about technology adoption. About either domestic or international suppliers, the questionnaire asks, "do any of these relationships with domestic suppliers result in technology transfer from the supplier to your enterprise?". Then, "if the answer is "yes", is the technology transfer mainly: (1) intentional and part of the legal contract, (2) intentional, but not part of the legal contract, (3) unintentional?". Concerning either domestic or international customers (to those domestic firms providing inputs), the questionnaire also asks similar questions. The TCS collects information from a consistent list of firms in 2011, 2012, and 2013, and thus, this gives the advantage for building a panel dataset. Some studies employ the TCS in their analyses, so far, such as Newman, Rand, Talbot and Tarp [24].

The TCS questionnaire also asks firms about constraints delaying or obstructing the enterprise's performance. Answers range from 0 to 10, in which 0 means "does not apply", 1 means "slightly important", and 10 means "very important". Specific constraints relate to (1) the basic infrastructure 
(electricity, energy, land), (2) the transport infrastructure (roads, airports), (3) the communication infrastructure, (4) the financing constraints (credits, foreign capital), (5) the labor force (number), (6) the technological know-how (skilled labor), and (7) technologies (machinery, equipment).

The second data source was the Vietnam Enterprise Survey (VES) in 2011, 2012, and 2013. The VES, which includes more enterprises than the TCS does, is collected by GSO. The survey information includes firm characteristics, location, industries, and especially detailed information about accounting and financial performance. Many pieces of research employ the VES in their analyses: Ngo and Nguyen [59], Newman, Rand, Talbot and Tarp [24], Anwar and Nguyen [60], and Anwar and Nguyen [61].

Our final sample derived from the two sources of the above datasets (TCS and VES) using the identifiers of firms consists of 3252 unbalanced Vietnamese domestic SMEs in 2011-2013. The unified dataset is unique, not only in Vietnam, but also in developing countries in transition.

\subsection{Methodology}

Figure 1 illustrates how technology adoptions along the supply chain (obtained through direct transfer of technology between linked firms) are defined.

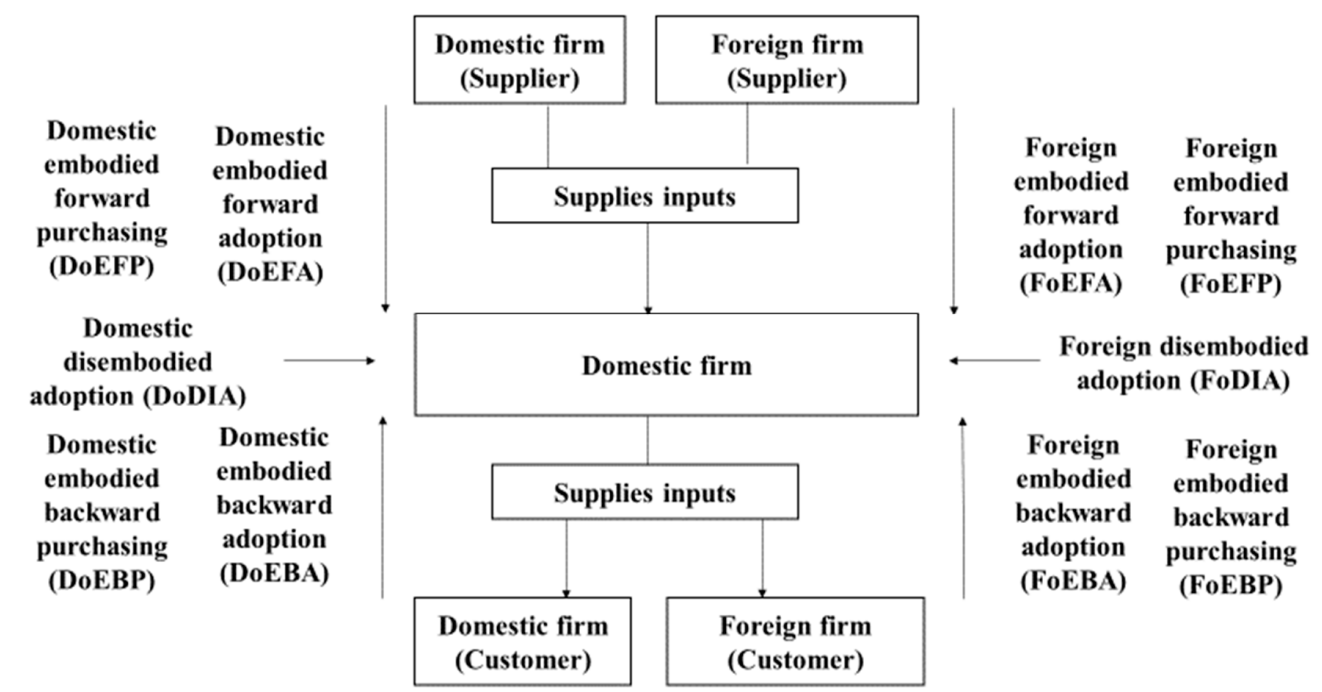

Figure 1. Definition of technology adoptions. Source: Authors' modification from Newman, Rand, Talbot and Tarp [24].

Technology adoptions include embodied and disembodied adoptions. Embodied technology adoption is intentional and a part of the legal contract, or intentional but not a part of the legal contract. Disembodied technology adoption is the unintentional one. Technology adoptions can also be divided by (1) forward linkage (technology is transferred from either domestic or foreign suppliers), (2) backward linkage (technology is transferred from either domestic or foreign customers), and (3) purchasing (in case of importing inputs from either domestic or foreign suppliers). In practice as in Figure 1, we define EBA as embodied adoption with backward linkage or when technology is transferred from either domestic (DoEBA) or foreign (FoEBA) customers to a domestic firm as a supplier. EBP is defined as embodied adoption with backward linkage or when technology is imported from either domestic (DoEBP) or foreign (FoEBP) customers to a domestic firm as a supplier. EFA is defined as embodied adoption with forward linkage or when technology is transferred from either domestic (DoEFA) or foreign (FoEFA) suppliers to a domestic firm as a customer. EFP is defined as the embodied adoption with a forward linkage of technology that is imported from either domestic (DoEFP) or foreign (FoEFP) suppliers to a domestic firm as a customer. Additionally, DIA is defined as technology purchased by a domestic firm from either domestic (DoDIA) or foreign (FoDIA) suppliers (disembodied adoption by a domestic firm). 
We established a set of five equations reflecting five technology adoption choices, namely: EBA, EBP, EFA, EFP, and DIA. The model for each choice is as follows:

$\operatorname{Pr}$ (being a firm that adopted a particular technology from five choices $=1)=\operatorname{Pr}($ adopt $=1$; adopt the particular technology choice $=1 \mid x)=\operatorname{Pr}($ adopt the particular technology choice $=1 \mid$ adopt $=1, x)$ $X \operatorname{Pr}($ adopt $=1 ; x)$.

Hence, we apply a probit model correcting by sample selection. The main idea is that, in each particular market, firms adopt two decisions. First, they decide to adopt or not. Second, those firms that decide to adopt have to decide a particular technology adoption from a list of five choices. In the following part, we specify the two models.

The first equation considers the probability of a firm's decision to adopt. To be specific:

$$
y_{1 i t}=\left\{\begin{array}{c}
1 \text { if } y_{1 i}^{*}=f\left(x_{1 i} \beta_{1}+Z_{1 i} \delta_{1}+u_{1 i}\right)>0 \\
0 \text { otherwise }
\end{array}\right.
$$

where $y_{1 i}$ is a dummy variable, which indicates that a firm $i$ decides to adopt in time $t$. Variable $y_{1 i t}^{*}$ is a latent dependent variable, $x_{1 i t}$ are the determinants of the firm's adoption, $Z_{1 i}$ is a matrix of time-varying firm-specific control variables, $\beta_{1 t}$ and $\delta_{1 t}$ are the vector of coefficients to be estimated, and $u_{1 i t}$ is the error term which follows $N\left(0, \sigma^{2}{ }_{1}\right)$. A firm "it" will adopt if $y_{1 i t}^{*}$ is positive. Equation (1) includes the following set of explanatory variables $\left(x_{1 i}\right)$ : Size (sales lagged one period), Age (years of operation), ShareExp (export share in sales), FDIDomSup (firm having relationship with FDI domestic suppliers), FDIDomCus (firm having relationship with FDI domestic customers), BInfrasT (difficulties in terms of basic infrastructure such as electricity, energy, land), TranInfrasT (difficulties in terms of transport infrastructure such as roads, airports), ComInfrasT (difficulties in terms of communication infrastructure), FinT (difficulties in terms of financial constraints such as credits, foreign capital), LabornbT (difficulties in terms of the number of the labor force), KnowhowT (difficulties in terms of technological know-how, namely skilled labor), and TechT (difficulties in terms of technologies such as machinery, equipment), MarketShareP (market share at province level), MarketShareC (market share at country level), $\operatorname{ComP}$ (competition at province level), and Com C (competition at country level), as shown in Table 1-Panel A.

The second main equation is the probability of conducting a particular technology adoption from the five choices. The dependent variable $y_{2 i}$ is a dummy variable that takes a value equal to 1 when a firm decides to conduct a particular technology adoption choice. The second equation has the form below:

$$
y_{2 i}=\left\{\begin{array}{c}
1 \text { if } y_{2 i}^{*}=f\left(x_{2 i} \beta_{2}+Z_{2 i} \delta_{1}+u_{2 i}\right)>0 \\
0 \text { otherwise }
\end{array}\right.
$$

where $y_{2 i}^{*}$ is the latent dependent variable, $x_{2 i}$ are the determinants of conducting a particular technology adoption choice, $Z_{2 i}$ is a matrix of time-varying firm-specific control variables, $\beta_{2 t}$ and $\delta_{2 t}$ are the vector of coefficients to be estimated, and $u_{2 i}$ is the error term which follows $N\left(0, \sigma^{2}{ }_{2}\right)$. $y_{2 i}$ is observed only when $y_{1 i}^{*}$ is equal to 1 . Equation (2) depends on the following set of explanatory variables $\left(x_{2 i}\right)$ : Size (sales lagged one period), Age (years of operation), ShareExp (export share in sales), FDIDomSup (firm having a relationship with FDI domestic suppliers), FDIDomCus (firm having a relationship with FDI domestic customers), BInfrasT (difficulties in terms of basic infrastructure such as electricity, energy, land), TranInfrasT (difficulties in terms of transport infrastructure such as roads, airports), ComInfrasT (difficulties in terms of communication infrastructure), FinT (difficulties in terms of financial constraints such as credits, foreign capital), LabornbT (difficulties in terms of the number of the labor force), KnowhowT (difficulties in terms of technological know-how, namely skilled labor), and TechT (difficulties in terms of technologies such as machinery, equipment), as shown in Table 1-Panel B. Equations (1) and (2) might contain some commonly omitted variables and therefore the correlation term $\rho$ between $\mathrm{u}_{1}$ and $\mathrm{u}_{2}$ might be unequal to zero. This correlation may appear since those firms that adopt demonstrate non-unobserved characteristics, which make them conduct a particular technology adoption choice. 
Table 1. Variables in the technology adoption model and the model of particular technology adoption choices.

\begin{tabular}{|c|c|c|c|}
\hline \multirow[t]{2}{*}{ Variable } & \multirow[t]{2}{*}{ Description } & $\begin{array}{l}\text { Panel A: Technology } \\
\text { Adoption Model }\end{array}$ & $\begin{array}{l}\text { Panel B: Technology } \\
\text { Adoption Choices }\end{array}$ \\
\hline & & \multicolumn{2}{|c|}{ Mean (Standard Deviation); Number of Observations } \\
\hline \multicolumn{4}{|c|}{ Dependent Variable } \\
\hline Adopt & A firm decides to adopt or not $(=1)$ & $0.27(0.44) ; 12,004$ & \\
\hline Adoption choices & A firm conducts a particular technology adoption choice & & \\
\hline & $\operatorname{EBA}(=1)$ & & $0.50(0.50) ; 3252$ \\
\hline & $\operatorname{EBP}(=1)$ & & $0.09(0.28) ; 3252$ \\
\hline & EFA $(=1)$ & & $0.69(0.46) ; 3252$ \\
\hline & $\mathrm{EFP}(=1)$ & & $0.14(0.35) ; 3252$ \\
\hline & DIA $(=1)$ & & $0.03(0.17) ; 3252$ \\
\hline \multicolumn{4}{|c|}{ Independent Variable } \\
\hline Size & $\ln ($ sales). Variable lagged one period & $9.19(1.66) ; 11,994$ & 9.51 (1.67); 3251 \\
\hline Age & $\ln ($ age). Variable lagged one period & $2.11(0.37) ; 11,994$ & $2.09(0.37) ; 3250$ \\
\hline ShareExp & Export share in sales $(\%)$ & $9.87(27.17) ; 12,004$ & $10.80(27.95) ; 3252$ \\
\hline FDIDomSup & A firm having relationship with FDI domestic suppliers (Dummy) & $0.06(0.23) ; 12,004$ & $0.08(0.27) ; 3252$ \\
\hline FDIDomCus & A firm having relationship with FDI domestic customers (Dummy) & $0.14(0.34) ; 12,004$ & $0.16(0.37) ; 3252$ \\
\hline FDIDomSupTech & A firm having relationship with FDI domestic suppliers resulted in technology transfer (Dummy) & $0.01(0.11) ; 12,004$ & $0.04(0.20) ; 3252$ \\
\hline FDIDomCusTech & A firm having relationship with FDI domestic customers resulted in technology transfer (Dummy) & $0.02(0.14) ; 12,004$ & $0.07(0.28) ; 3252$ \\
\hline Constraints & Level of difficulties that delay or obstruct the realization of technology in terms of $(0=$ does nc & apply, 1 = slightly import & $=$ very important): \\
\hline BInfrasT & Basic infrastructure & $5.3(3.7) ; 12,004$ & $5.8(3.7) ; 3251$ \\
\hline TranInfrasT & Transport infrastructure & $4.3(3.4) ; 12,004$ & $4.6(3.4) ; 3251$ \\
\hline ComInfrasT & Communication infrastructure & $3.7(3.2) ; 12,004$ & $4.0(3.3) ; 3251$ \\
\hline FinT & Financial constraints & $6.4(3.37) ; 12,004$ & $6.7(3.3) ; 3251$ \\
\hline LabornbT & Number of labor force & $4.95(3.31) ; 12,004$ & $5.2(3.3) ; 3251$ \\
\hline KnowhowT & Technology know-how & $5.59(3.23) ; 12,004$ & $5.9(3.2) ; 3251$ \\
\hline TechT & Technologies & $5.82(3.38) ; 12,004$ & $6.2(3.3) ; 3251$ \\
\hline Market share & \multicolumn{3}{|l|}{ Market variables which indicate: } \\
\hline MarketShareP & The market share gained by the firm at the province level (\%) & & 24.64 (28.66); 3252 \\
\hline MarketShareC & The market share gained by the firm at the country level (\%) & & $21.19(26.18) ; 3252$ \\
\hline Competition & \multicolumn{3}{|l|}{$\begin{array}{l}\text { Level of competition faced by the firm: } \\
\end{array}$} \\
\hline ComP & The number of competitors at the province level & & 16.63 (43.76); 3252 \\
\hline $\mathrm{ComC}$ & The number of competitors at the country level & & 13.63 (53.16); 3252 \\
\hline
\end{tabular}

Note: Technology adoption choices: embodied backward adoption (EBA), embodied backward purchasing (EBP), embodied forward adoption (EFA), embodied forward purchasing (EFP), and disembodied adoption (DIA). Source: Author's suggestion. 
Following the works of Newman, Rand, Talbot and Tarp [24], Giroud, Jindra and Marek [33], Smeets [32], and Marin and Bell [62], we go further by examining FDI spillovers in two ways. Specifically, first, we examine the direct adoption impact of linkages and direct technology transfers from FDI. This is operated through the estimation of Equations (3) and (4):

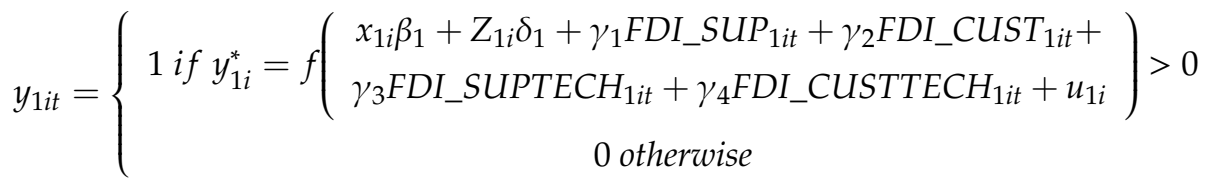

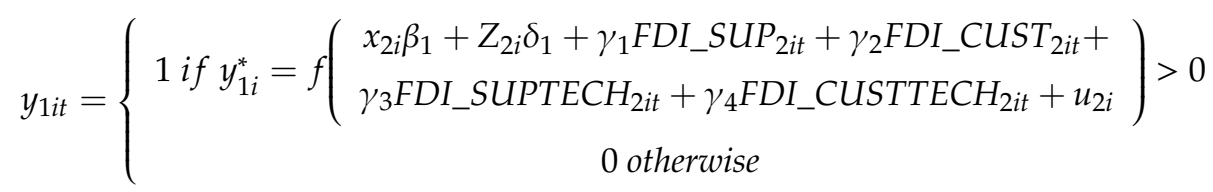

where FDI_SUP takes the value 1 if the firm is supplied by an FDI firm (0, otherwise), and FDI_CUST takes the value 1 if the firm has an FDI firm as a customer (0, otherwise). FDI_SUPTECH and FDI_CUSTTECH take the value 1 when the firm received technology transfers from FDI suppliers and FDI customers, respectively ( 0 , in other cases).

Second, we examine the effects of the economic constraints used in Equation (4), given the direct linkage between FDI and domestic firms and FDI technology transfer as suggested by Newman, Rand, Talbot and Tarp [24]. In other words, we explore the interaction between economic constraints and the status of direct linkage with foreign firms in the supply chain. The estimation model is given in Equations (5) and (6).

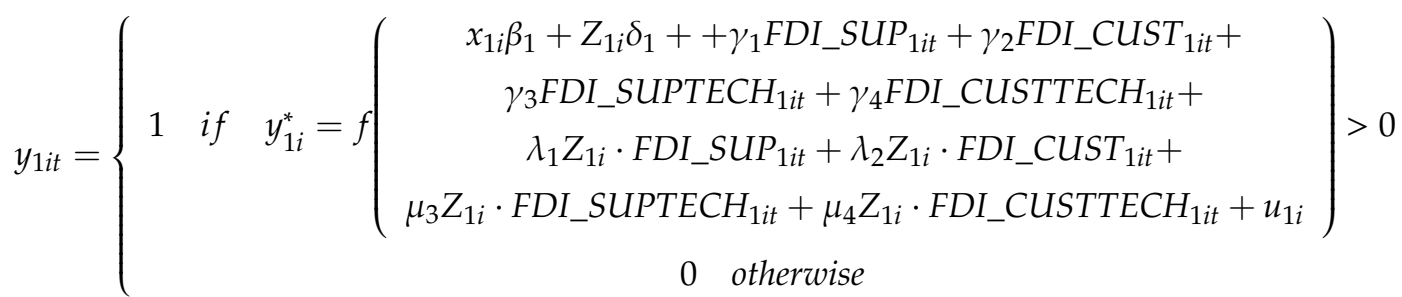

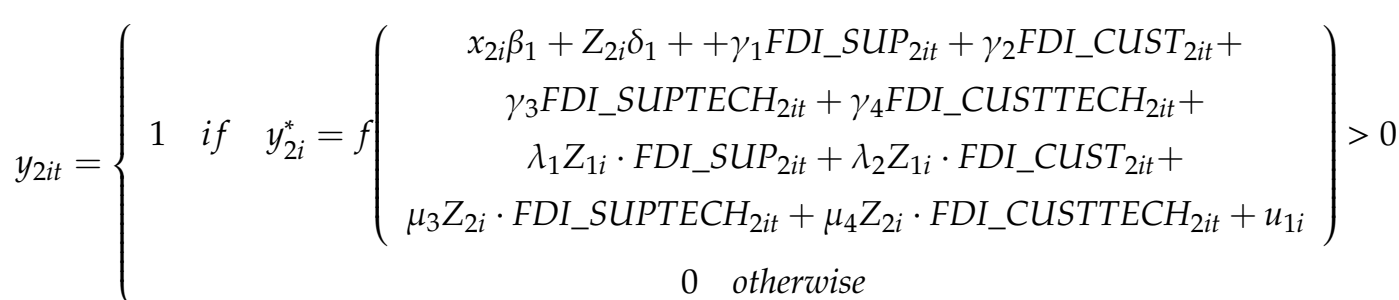

The current paper applies the Mundlak-Chamberlain approach (Mundlak [63], Chamberlain [64]), which includes two steps as follows:

Step 1: Estimate three different selection probit models (i.e., use pooled probit) and compute three inversed Mills ratios.

Step 2: Estimate a system of equations with three inversed Mills ratios on the selected sample (i.e., use panel probit). This yields consistent estimates of coefficients.

\section{Empirical Analysis}

\subsection{Descriptive Statistics}

Table 2 shows a sample of young SMEs. The database has 12,004 observations in the three-year unbalanced panel. The percentage of YACs accounts for around 27.35 percent of the sample in 2011, and this indicator reduces to 19.12 percent in 2013. For young non-adoption companies (YNACs), the value is around 72.65 percent in 2011, and it is equal to 80.88 percent in 2013. 
Table 2. Distribution of sample of young SMEs, 2011-2013.

\begin{tabular}{cccc}
\hline \multirow{2}{*}{ Year } & \multicolumn{3}{c}{ Young SME Sample } \\
\cline { 2 - 4 } & YACs, $\mathbf{n}(\mathbf{\%})$ & YNACs, $\mathbf{n}(\mathbf{\%})$ & Full Sample, N (\%) \\
\hline 2011 & $1099(27.35)$ & $2919(72.65)$ & $4018(100.00)$ \\
2012 & $1389(34.84)$ & $2595(65.16)$ & $3984(100.00)$ \\
2013 & $765(19.12)$ & $3237(80.88)$ & $4002(100.00)$ \\
\hline Total & $3252(27.09)$ & $8752(72.91)$ & $12,004(100.00)$ \\
\hline
\end{tabular}

Note: YACs: young adoption companies, YNACs: young non-adoption companies. Source: Author's calculation from Vietnam Technology and Competitiveness Survey (TCS) and Vietnam Enterprise Survey (VES).

Table 3 shows the distribution of the sample of young SME adoption. The database has 3252 observations in the three-year unbalanced panel. The five different technology adoption strategies include: (1) embodied backward adoption (EBA), (2) embodied backward purchasing (EBP), (3) embodied forward adoption (EFA), (4) embodied forward purchasing (EFP), and (5) disembodied adoption (DIA).

Table 3. Distribution of technology adoption SMEs, 2011-2013.

\begin{tabular}{ccccccc}
\hline \multirow{2}{*}{ Year } & \multicolumn{5}{c}{ Technology Adoption SME Sample } \\
\cline { 2 - 6 } & EBA, n (\%) & EBP, n (\%) & EFA, n (\%) & EFP, n (\%) & DIA, n (\%) & Sample, N (\%) \\
\hline 2011 & $648(39.54)$ & $109(37.98)$ & $782(34.94)$ & $142(31.56)$ & $39(38.61)$ & $1099(33.78)(100.00)$ \\
2012 & $561(34.23)$ & $99(34.49)$ & $1124(50.22)$ & $107(23.78)$ & $42(41.58)$ & $1389(42.70)(100.00)$ \\
2013 & $430(26.24)$ & $79(27.53)$ & $332(14.83)$ & $201(44.67)$ & $20(19.80)$ & $765(23.52)$ \\
\hline Total & $1639(100.00)$ & $287(100.00)$ & $2238(100.00)$ & $450(100.00)$ & $101(100.00)$ & $3252(100.00)(100.00)$ \\
\hline
\end{tabular}

Note: Technology adoption choices are defined in Table 1. Source: Author's calculation from TCS and VES.

The percentage of EBAs represents around 39.51 percent of the sample in 2011, while this value reduces to 26.22 percent in 2013. With respect to EBPs, the value is around 37.98 percent in 2011, and it is equal to 27.53 percent in 2013. Regarding EFAs, the value is around 34.94 percent in 2011, and it is equal to 14.83 percent in 2013. Concerning EFPs, the percentage is around 31.65 in 2011, and it is equal to 44.67 percent in 2013. About DIAs, the proportion is around 38.61 percent in 2011, and in 2013, it is equal to 19.80 percent.

Table 4 shows the main characteristics of six groups of firms-five types of YACs and YNACs. We observe differences among YACs and with their counterparts in profiles as follows.

Regarding firm characteristics, first, YACs (including EBA, EBP, EFA, EFP, and DIA) have a higher number of workers and capital volume (both total assets and equity in absolute terms) than YNACs, while the mean size of the other firms has the lowest value regardless of whether we consider the number of employees or volumes of total assets and equity. Second, in reference to the sales volumes, YACs have higher volumes in absolute terms than both YNACs and other firms. Third, in relation to the age, firms with EBA, EFA, or DIA are younger than YNACs, while EBP and EFP are older. Fourth, concerning the openness to international trade, EBP is more internationally tradable in terms of both exports and imports, EFP is more in terms of imports, while other YACs are less internationally tradable than YNACs in terms of both exports and imports. 
Table 4. Descriptive summary, young SMEs (average 2011-2013).

\begin{tabular}{|c|c|c|c|c|c|c|}
\hline \multirow{2}{*}{ Variable } & EBA & EBP & EFA & EFP & DIA & YNACs \\
\hline & (1) & (2) & (3) & (4) & (5) & (6) \\
\hline Sales (mill. VND) & $39,367.78(75,630.74)$ & $\begin{array}{l}86,798.56^{\mathrm{a}^{* * *}} \\
(156,677.74)\end{array}$ & $\begin{array}{l}49,128.39^{b^{* * *}} \\
(159,191.45)\end{array}$ & $\begin{array}{c}121,226.02^{\mathrm{a}^{* * *}, \mathrm{c}^{* * *}} \\
(312,977.25)\end{array}$ & $\begin{array}{c}87,291.87^{\mathrm{a}^{* * *}, \mathrm{c}^{* *}} \\
(299,176.99)\end{array}$ & $\begin{array}{c}38,210.49^{b^{* * *}, c^{* * *}, d^{* * *}, e^{* * *}} \\
(133,013.74)\end{array}$ \\
\hline Employees (persons) & $54.64(57.88)$ & $120.9256^{\mathrm{a}^{* * *}}(88.51)$ & $66.98^{a^{* * *}, b^{* * *}}(67.75)$ & $\begin{array}{c}96.35^{\mathrm{a}^{* * *}, \mathrm{~b}^{* * *}, \mathrm{c}^{* * *}} \\
(76.93)\end{array}$ & $\begin{array}{c}65.99 \mathrm{a}^{*}, \mathrm{~b}^{* * *}, \mathrm{~d}^{* * *} \\
(64.59)\end{array}$ & $\begin{array}{c}51.59 \mathrm{~b}^{* * *}, \mathrm{c}^{* * *}, \mathrm{~d}^{* * *}, \mathrm{e}^{* * *} \\
(57.71)\end{array}$ \\
\hline Age (years) & $8.67(2.87)$ & $9.10(2.88)$ & $8.41^{\mathrm{a}^{* *}, \mathrm{~b}^{* * *}}(2.79)$ & $9.44^{\mathrm{a}^{* * *}, \mathrm{c}^{* * *}}(2.89)$ & $\begin{array}{c}7.81^{a^{* * *}, b^{* * *}, c^{* *}, d^{* * *}} \\
(2.69)\end{array}$ & $8.83^{\mathrm{c}^{* * *}, \mathrm{~d}^{* * *}, \mathrm{e}^{* * *}}(2.88)$ \\
\hline Assets (mill. VND) & $35,910.19(90,670.05)$ & $\begin{array}{c}68,181.6256^{\mathrm{a}^{* * *}} \\
(123,756.93)\end{array}$ & $\begin{array}{c}38,550.45^{,} b^{* * *} \\
(102,415.20)\end{array}$ & $\begin{array}{c}90,013.56^{\mathrm{a}^{* * *}, \mathrm{c}^{* * *}} \\
(153,390.26)\end{array}$ & $\begin{array}{c}52,724.70^{a^{*}, d^{* *}} \\
(109,551.72)\end{array}$ & $\begin{array}{c}29,183.43^{b^{* * *},}, c^{* * *}, d^{* * *}, e^{* *} \\
(110,827.72)\end{array}$ \\
\hline Equity (mill. VND) & $12,517.91(33,763.83)$ & $\begin{array}{c}23,038.2856^{\mathrm{a}^{* * * *}} \\
(46479.54)\end{array}$ & $\begin{array}{c}12,847.17^{\mathrm{b}^{* * *}} \\
(35,334.41)\end{array}$ & $\begin{array}{c}30,523.78^{a^{* * *}, c^{* * *}} \\
(52,789.27)\end{array}$ & $\begin{array}{c}18,119.24 \mathrm{~d}^{* *} \\
(41,365.17)\end{array}$ & $\begin{array}{c}10,112.24^{b^{* * *}, c^{* * *}, d^{* * *}, e^{* *}} \\
(37,449.70)\end{array}$ \\
\hline Firm exports (\%) & $84(37)$ & $94^{\mathrm{a}^{* * *}}(24)$ & $78^{a^{* * *}, b^{* * *}}(41)$ & $83^{b^{* * *}, c^{* *}}(38)$ & $82^{b^{* * *}}(38)$ & $87^{a^{*}, b^{* *}, c^{* * *}, d^{* *}}(34)$ \\
\hline Firm imports (\%) & $87(34)$ & $90(31)$ & $79^{a^{* * *}, b^{* * *}}(41)$ & $92^{\mathrm{a}^{* *}, \mathrm{c}^{* * *}}(28)$ & $86^{\mathrm{c}^{*}, \mathrm{~d}^{*}}(35)$ & $87^{\mathrm{c}^{* * *}, \mathrm{~d}^{* * *}}(33)$ \\
\hline
\end{tabular}

Note: Standard deviation in brackets; a, b, c, d, e: statistically significant compared to EBA, EBP, EFA, EFP, DIA, respectively; ${ }^{*} p<0.10,{ }^{* *} p<0.05,{ }^{* * *} p<0.01$. Technology adoption choices are defined in Table 1; YNACs: young non-adoption companies. Source: Author's calculation from TCS and VES. 
Regarding constraints delaying or obstructing the enterprise's performance, as shown in Figure 2, firstly, in general, larger percentages of YACs state that they suffer most of the constraints in basic infrastructure (electricity, energy, land), transport infrastructure (roads, airports), communication infrastructure, financing (credits, foreign capital), the labor force (number of laborers), technological know-how (skilled labor), and technologies (machinery, equipment) than YNACs do. Secondly, similarly, larger percentages of a firm with EBA, EBP, EFA, EFP state that they suffer most of the constraints than firms with DIA do. Thirdly, larger percentages of firms with EBA and EBP state that they suffer severer constraints in basic infrastructure, financing, labor force, and technological know-how. Fourth, a larger percentage of firms with EBP state that they suffer severer constraints in technological know-how, while a larger percentage of firms with EFP state that they suffer severer constraints in technologies.

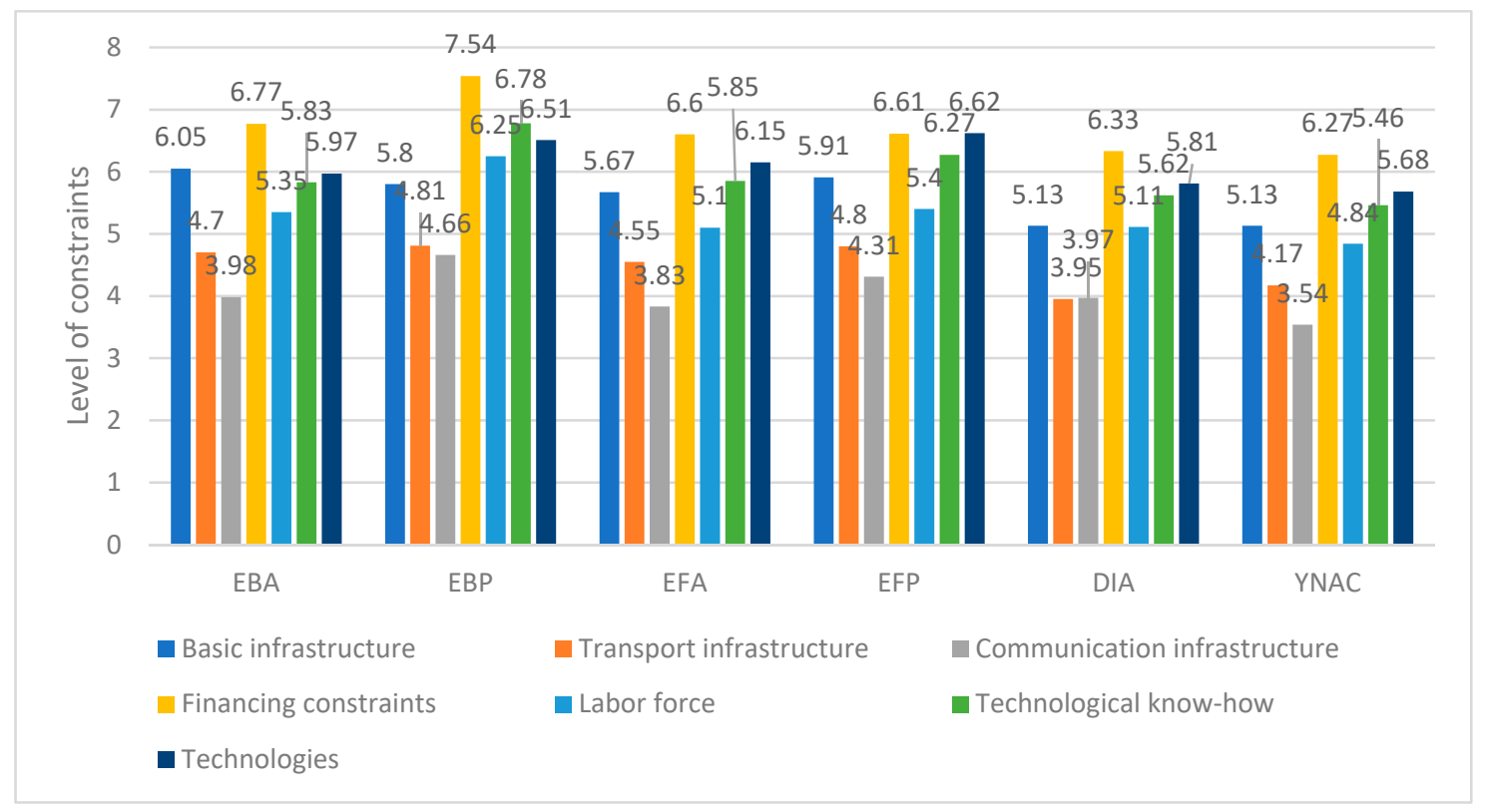

Figure 2. Constraints on young SMEs' economic performance; average points over 2011-2013. Note: Seven types of constraints: (1) basic infrastructure (electricity, energy, land), (2) transport infrastructure (roads, airports), (3) communication infrastructure, (4) financing (credits, foreign capital), (5) labor force (number of laborers), (6) technological know-how (skilled labor), and (7) technologies (machinery, equipment). The level of constraints is measured as average points of each constraint (range from 0 to 10). Source: Authors' calculation from TCS.

The business environment can affect spillovers in some ways. One that has been detailed in the literature as particularly important is that of competition, with a positive correlation between competition and the strength of spillovers. Abraham, et al. [65] concluded that spillovers were only positive in sectors with greater levels of competition. It appears that competition acts as a catalyst through which domestic firms improve their performance (as mentioned by Wang, et al. [66]). This may be the result of increased numbers of competitors promoting quality improvements to attract customers or cost minimization to reduce price and gain market share.

Firms with EBP, EFA, EFP, and DIA report fewer competitors at the provincial level than YNACs do, as shown in Figure 3. Firms with EBP and EFA also report fewer competitors at the national level than YNACs do. However, firms with EFP and DIA report more competitors at the national level than YNACs do. This indicates that firms with EFP and DIA tend to be more expansive in the competitive national market. Firms with EBA face the highest competitors at the international level than any other YACs and YNACs do. 


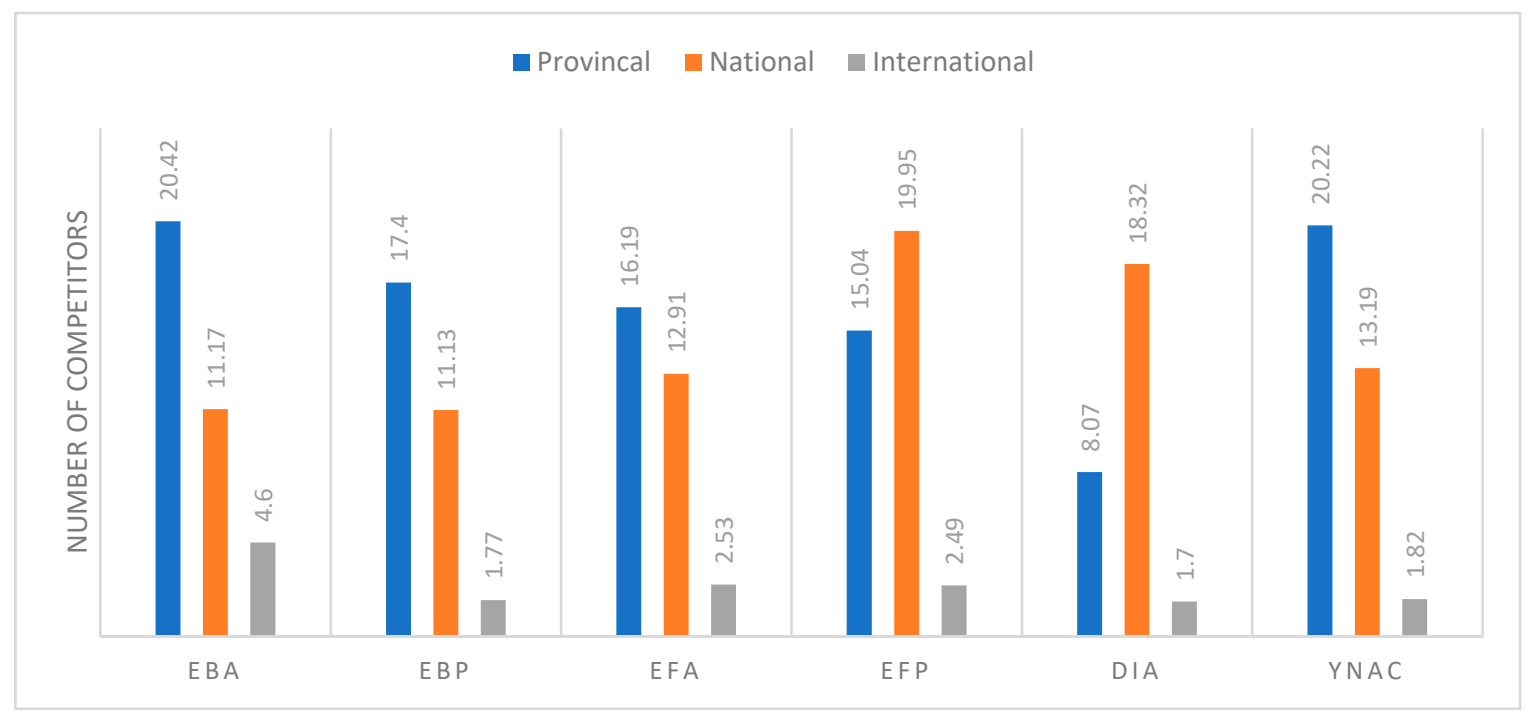

Figure 3. Average number of competitors by YACs and YNACs, 2011-2013. Note: YACs: young adoption companies, YNACs: young non-adoption companies. Technology adoption choices are defined in Table 1. Source: Authors' calculation from TCS.

Furthermore, larger percentages of firms with EBA, EFA, EFP, and DIA state that they face competition in the main field of activity, as shown in Figure 4. A larger percentage of firms with DIA state that their market shares of main activity are within a province. A larger percentage of YNACs state that their market shares of main activity are within the country. It is noted that a larger percentage of YNACs and firms with a DIA status are "price taker" firms, while obviously, we observe ahigher percentage of "limited autonomy" or "significant autonomy in setting prices" for some YACs, such as firms with EBA, EBP, EFP.

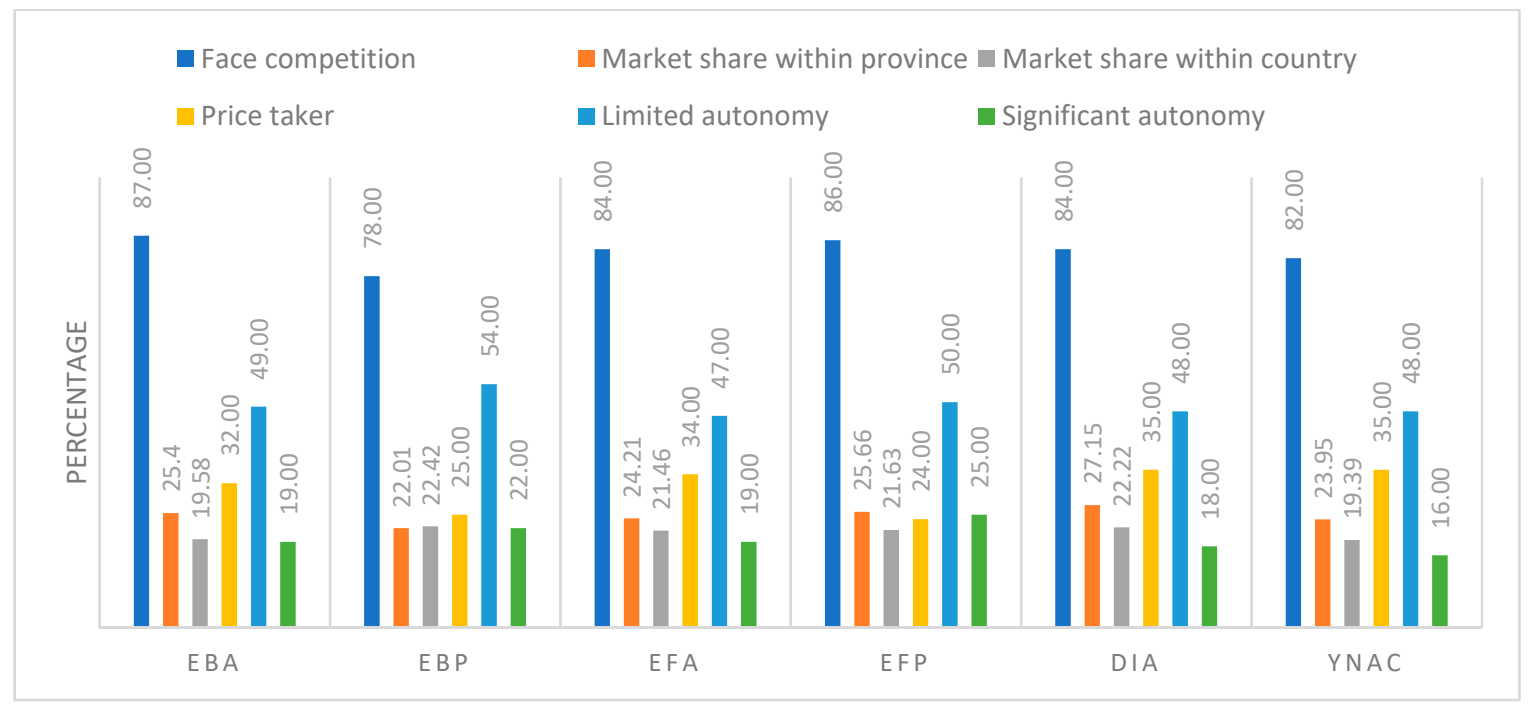

Figure 4. Competition and firms' market power by YACs and YNACs; average percentage over 2011-2013. Note: YACs: young adoption companies, YNACs: young non-adoption companies. Technology adoption choices are defined in Table 1. Source: Authors' calculation from TCS.

To summarize, we find that firms differ substantially in terms of the number of workers, age, physical capital intensity, sales volumes (growth ability), and openness to international trade. These attributes capture a firm's capability to acquire and absorb newly acquired technology. Second, firms face different constraints on their economic performance. Third, firms face different levels of 
competition. In the following, we will present an econometric framework in which the differences in technology adoption behavior are linked to the differences in constraints on their economic performance along the supply chain and technology transfer.

\subsection{Empirical Results}

The overall aim of our analysis was to determine the extent to which a particular technology adoption choice by young domestic SMEs is related to economic constraints, FDI linkages, and FDI technology transfer. We began by estimating the basic specification of economic constraints, FDI linkages, and FDI technology transfer given in Equation (4) and obtain the results in Table 5. The three inverse Mills ratios in models of EBA, EBP, EFA, and EFP are significant at the 1 percent level, indicating that the estimated coefficients are consistent after correcting the selection sample problem.

We find that a firm with FDI domestic customers resulted in technology transfer (technology transfer through backward linkages) is more likely to adopt EBA. However, a firm only having a linkage with FDI domestic customers is less likely to adopt EBA. We also find that a firm with FDI domestic suppliers is more likely to adopt EFP. A firm with FDI domestic suppliers resulted in technology transfer (technology transfer through forward linkages) is more likely to adopt EFA. However, a firm only having a linkage with FDI domestic suppliers is less likely to adopt EFA. These findings confirm the importance of interactions between domestic and FDI firms in the process of technology adoption as suggested in the literature of adoption (Glass and Saggi [21], Wang and Blomström [23]).

With respect to firm characteristics, firm size shows significant positive coefficients in models EBP and EFP, which is in line with the study of Vishwasrao and Bosshardt [37] with Indian data from 1989 to 1993. Our findings interestingly show that, while firm size plays a positive impact on the probability of becoming an EBP or EFP, the effect vanishes in the case of becoming a DIA. The positive impact of firm size has also been found in Scherer [67], Kamien and Schwartz [68], Katz and Shapiro [69], Loury [70], Fudenberg and Tirole [45], and Chang and Robin [18]. The negative impact of firm age in models EBA, EFA, and DIA shows that older firms are more incentivized to spend small efforts to conduct such EBA, EFA, and DIA activities, and this has been found in Vishwasrao and Bosshardt [37], and Pandit and Siddharthan [55]. However, the positive sign of the firm's years of operation in model EFP shows that long-lasting firms are more likely to devote big efforts to spend money in EFP activities. This result is also found in the study of Vishwasrao and Bosshardt [37] and Siddharthan and Safarian [54].

Regarding the export orientation, we find interesting results between particular technology adoption choices. While both EBA and EFA firms show a significantly negative impact, the impact is significantly positive for the likelihood of being an EBP. That means exporting firms do not tend to conduct embodied backward or embodied forward adoptions, but they are more likely to adopt embodied backward technology through purchasing. The explanation may come from a fact that firms in an internationally competing market already have a competitive product or competitive productivity. Hence, we may notice that young small exporting firms are not inclined to choose an EBA or EFA and thereby decrease the dangers that can harm their competitive product or competitive productivity.

With reference to the domestic competitiveness of the firm proxied by the number of province-level competitors, the impact follows an inverse U-shaped pattern for the probability of being an EBA, but a U-shaped pattern for the probability of being a DIA. Our results indicate that the level of competitiveness likely increases the possibility of being an EBA, while decreases the likelihood of being a DIA at the first stage of growth. At the later stage, the level of competitiveness likely decreases the probability of being an EBA, while increasing the probability of being a DIA. The finding of significant competition's role is in line with Scherer [67], Kamien and Schwartz [68], Katz and Shapiro [69], Loury [70], and Fudenberg and Tirole [45].

Concerning the market power in terms of the market share at the national level, we also observe a significantly inversed U-shaped pattern for the probability of being an EBA. Our results indicate that the volumes of the market power likely increase the probability of being an EBA at the first stage of growth and decrease the probability of being an EBA at the later stage of growth. This is in accordance 
with what [67] found-technology transfer is spurred by competition, but that too much competition does not allow payment for the transfer. An explanation may be when a firm has more market power, it may have less competition incentive to invest more in technology transfer, even if it can have more financial resources to do so.

The significantly negative influence has been found: the barriers of basic infrastructure (such as electricity, energy, land) on the probability of being an EBP, communication infrastructure (such as road, airports) on EBP, the labor force (number of laborers) on EFA, technologies (such as machinery, equipment) on EBA as expected in the literature of adoption. However, the significantly positive effect has been found on the barriers of communication infrastructure on the probability of being an EBP or a DIA, financial constraints (such as credits, foreign capital) on EBA, labor force on EBA, technological know-how (skilled labor) on EFA. Hence, in the case of communication infrastructure, our results may suggest that this type of constraint pushes firms to look for sources of technology that may not depend on communication infrastructure or even ease the lack of communication infrastructure. In the case of financial constraints, this type of constraint pushes firms to look for other sources of financing or to switch between internal and external financial sources. A constraint in the labor force, on the other hand, stimulates firms to engage in a type of embodied technology transfer. In the same vein, constraint in technological know-how, on the other hand, stimulates firms to engage in a type of embodied technology transfer.

Table 5. Impact of constraints, foreign direct investment (FDI) linkage and vertical spillovers (marginal effect), 2011-2013.

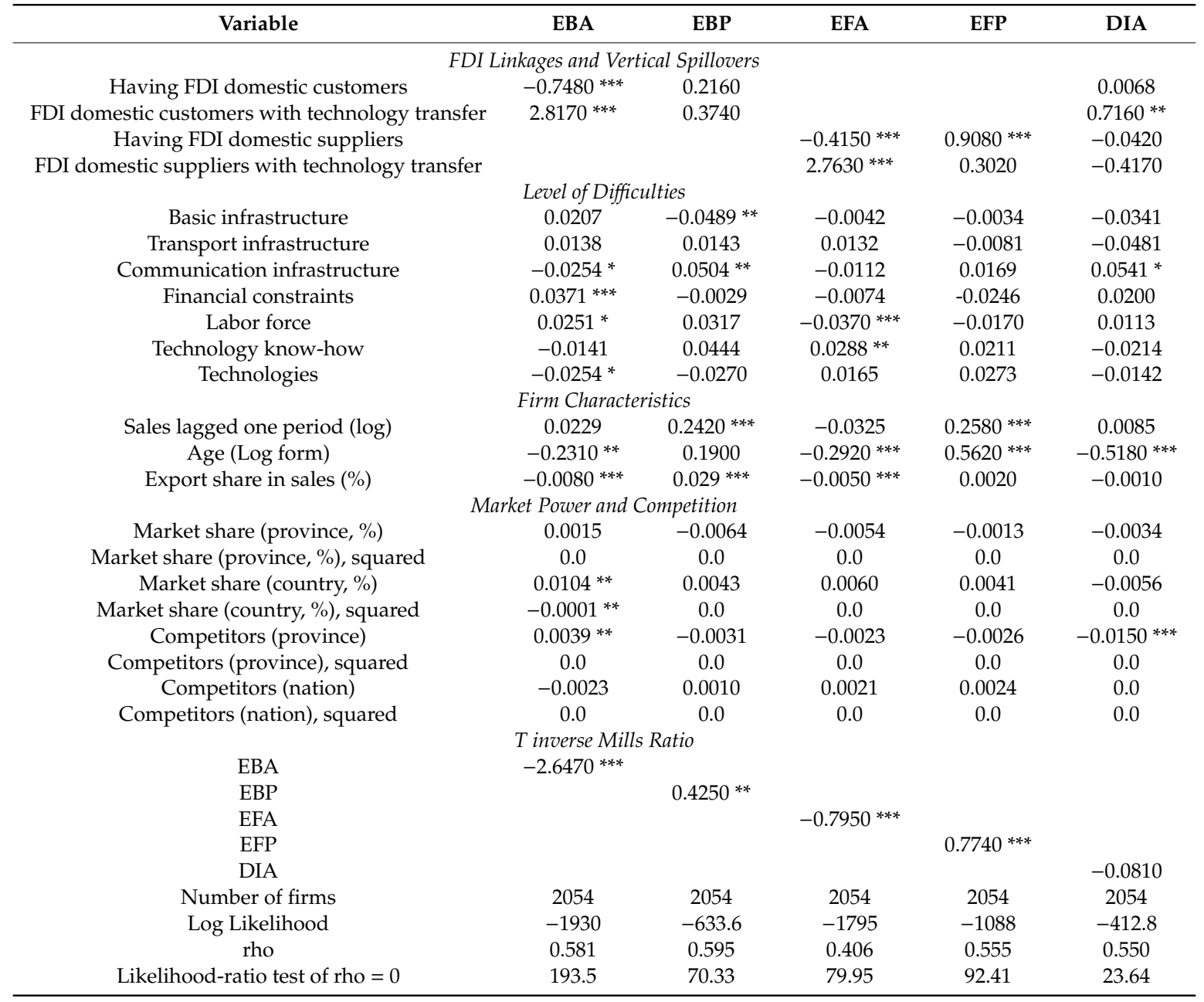

Note: Each model is estimated using random effects. ${ }^{*} p<0.10,{ }^{* *} p<0.05,{ }^{* * *} p<0.01$. 0.0 : Very small. Technology adoption choices are defined in Table 1. Source: Authors' estimation from TCS and VES. 
We then continue to look at the indirect effects by estimating the interaction specification of economic constraints, FDI linkages, and FDI technology transfer following Equation (6) in Table 6. The three inverse Mills ratios in models of EBA, EBP, EFA, and EFP are significant at the 1 percent level, indicating that the estimated coefficients are also consistent after correcting the selection sample problem.

Table 6. Impact of interactions between constraints and FDI linkage and vertical spillovers (marginal effect), 2011-2013.

\begin{tabular}{|c|c|c|c|c|c|}
\hline Variable & EBA & EBP & EFA & EFP & DIA \\
\hline \multicolumn{6}{|c|}{ Interactions with FDI Domestic Suppliers } \\
\hline Basic infrastructure & & & -0.0835 & 0.0189 & -0.1160 \\
\hline Transport infrastructure & & & $0.1380 *$ & 0.0833 & 0.0352 \\
\hline Communication infrastructure & & & -0.0299 & 0.0024 & 0.3010 \\
\hline Financial constraints & & & 0.0174 & -0.0735 & 0.0063 \\
\hline Labor force & & & 0.0868 & -0.0781 & 0.0144 \\
\hline Technology know-how & & & -0.1060 & 0.0541 & 0.3390 * \\
\hline Technologies & & & -0.0456 & 0.0207 & -0.2810 \\
\hline \multicolumn{6}{|c|}{ Interactions with FDI Domestic Customers } \\
\hline Basic infrastructure & -0.0415 & 0.0007 & & & 0.0707 \\
\hline Transport infrastructure & 0.0763 & -0.0825 & & & -0.0481 \\
\hline Communication infrastructure & -0.0131 & -0.0157 & & & $-0.3350 * *$ \\
\hline Financial constraints & 0.0452 & 0.1140 & & & -0.1560 \\
\hline Labor force & 0.0699 & 0.0428 & & & $0.2220^{* *}$ \\
\hline Technology know-how & $-0.1430 * *$ & 0.0124 & & & -0.0150 \\
\hline Technologies & 0.0252 & 0.0863 & & & 0.0913 \\
\hline \multicolumn{6}{|c|}{ Interactions with FDI Domestic Suppliers Resulted in Technology Transfer (Vertical Spillovers through forward Linkages) } \\
\hline Basic infrastructure & & & 224.2000 & 0.0467 & -0.1550 \\
\hline Transport infrastructure & & & -105.8000 & 0.0265 & 0.3860 \\
\hline Communication infrastructure & & & 27.3500 & -0.0526 & $-0.6360 *$ \\
\hline Financial constraints & & & -12.7000 & 0.0396 & 0.1210 \\
\hline Labor force & & & -53.1200 & -0.0225 & 0.5030 \\
\hline Technology know-how & & & 38.6500 & -0.0637 & -0.3860 \\
\hline Technologies & & & 53.0800 & -0.0037 & -0.2500 \\
\hline \multicolumn{6}{|c|}{ Interactions with FDI Domestic Customers Resulted in Technology Transfer (Vertical Spillovers through Backward Linkages) } \\
\hline Basic infrastructure & 0.0312 & -0.1520 & & & -0.1140 \\
\hline Transport infrastructure & 0.0557 & -0.0099 & & & -0.1220 \\
\hline Communication infrastructure & 0.0203 & 0.0478 & & & 0.2460 \\
\hline Financial constraints & -0.0867 & -0.0754 & & & 0.1910 \\
\hline Labor force & 0.1340 & 0.1250 & & & $-0.2920 * *$ \\
\hline Technology know-how & 0.0695 & -0.1660 & & & -0.0100 \\
\hline Technologies & -0.1440 & 0.1230 & & & 0.1310 \\
\hline Number of firms & 2054 & 2054 & 2054 & 2054 & 2054 \\
\hline Log Likelihood & -1920 & -622.6 & -1766 & -1123 & -392.9 \\
\hline rho & 0.584 & 0.600 & 0.429 & 0.521 & 0.537 \\
\hline Likelihood-ratio test of rho $=0$ & 190.2 & 70.32 & 82.09 & 83.39 & 19.96 \\
\hline
\end{tabular}

Note: Each model is estimated using random effects. Time-varying firm-level control variables included in Table 6 are also included here but are not presented for ease of expression. They are available on request. ${ }^{*} p<0.10$, ${ }^{* *} p<0.05,{ }^{* * *} p<0.01$. Technology adoption choices are defined in Table 1. Source: Authors' estimation from TCS and VES.

We find that among firms with FDI domestic suppliers, the significantly positive influence has been found on the barriers of transport infrastructure on the probability of being an EFA, and technology know-how on DIA. Second, among firms with FDI domestic customers, the significantly negative effect has been found on the barriers of communication infrastructure on the probability of being at DIA, and technological know-how on EBA as expected in the literature of adoption. However, the significantly positive impact has been found on the barriers of the labor force on the probability of being a DIA. A constraint in the labor force, on the other hand, stimulates firms to engage in a type of embodied technology transfer. Third, among firms with FDI domestic suppliers resulting 
in technology transfer (technology transfer through forward linkages), the significantly negative impact has been found on the barriers of communication infrastructure on the probability of being a DIA as expected in the literature of adoption. Fourth, among firms with FDI domestic customers resulting in technology transfer (technology transfer through backward linkages), the significantly negative impact has been found on the barriers of the labor force on the probability of being a DIA as expected in the literature of adoption.

\section{Conclusions}

SMEs' technology adoption is crucial to increase long-term productivity. However, empirical evidence related to young private SMEs' adoption is mixed and this is a problem for designing effective support schemes. This article aimed to examine the impacts of direct linkages and technology transfer between FDI firms and young SMEs that cause different technology adoption strategies along the supply chain (through direct transfer of technology between linked firms) by YACs. Five different technology adoption strategies considered were the embodied backward adoption, the embodied backward purchasing, the embodied forward adoption, the embodied forward purchasing, and the disembodied adoption. Throughout the research, the current paper distinguished technology transfers from technology spillovers. The dataset consisted of a sample with 3253 Vietnamese young SMEs in the period 2010-2013. We estimated the panel probit model controlling for the sample selection since firms that decide to adopt are different in comparison with the other firms.

The analysis results highlight the importance of direct linkages, technology transfer between FDI firms and young SMEs, economic obstacles, and the interactions between them that cause young SMEs to conduct technology adoption strategies in the supply chain (obtained through direct transfer of technology between linked firms). Specifically, our results indicate that exporting firms do not tend to conduct embodied backward or embodied forward adoptions but are more likely to adopt the embodied backward technology through purchasing. In addition, our results indicate that the impact of the level of competitiveness follows an inverse U-shaped pattern for the probability of being an embodied backward adoption, but a U-shaped pattern for the probability of being a disembodied adoption. In terms of market power, our results point out a significantly inversed U-shaped pattern for the probability of being an embodied backward adoption. The significantly negative impact has been found on the barriers of basic infrastructure on the probability of being an embodied backward adoption, communication infrastructure on the probability of an embodied backward purchasing, labor force on the probability of an embodied forward adoption, and technologies on the probability of being an embodied backward adoption. Firms that overcome some barriers in communication infrastructure, financial constraints, labor force, and technological know-how may look for other sources of technology that may not depend on communication infrastructure, or to switch between internal and external financial sources, and/or to engage in a type of embodied technology transfer.

Under the impact of FDI linkages and vertical spillovers, the current paper finds that technology transfer through backward linkages is associated with the embodied backward adoption and that technology transfer through forward linkages is likely associated with the embodied forward adoption. However, a linkage with FDI domestic customers is less likely associated with the embodied backward adoption, and linkage with FDI domestic suppliers is less likely associated with the embodied forward adoption. With respect to economic constraints, we find that, under a linkage with FDI domestic suppliers, the barrier of communication infrastructure is negatively associated with the disembodied adoption and technological know-how with the embodied backward adoption. Moreover, firms can overcome some barriers in transport infrastructure and the labor force, owing to the linkages with FDI domestic customers and/or suppliers. Finally, we find that under technology transfer through forward linkages, the barrier of communication infrastructure is negatively associated with the disembodied adoption, and under technology transfer through backward linkages, the barrier of the labor force is negatively associated with the disembodied adoption. 
While policies aiming to promote young SMEs' technology adoption obtain a consensus, it is less understandable why firms decide to undertake different types of technology choices. The technology linkages and firm's characteristics influence the firm's adoption behavior. Therefore, concerning policies must be aware that indifferent incentives may not reach the outcomes for young SMEs. Important equally, policy-makers must consider a broader range of sectoral characteristics that may influence adoption behavior, such as export orientation, competitiveness, and market power.

While the attempt to breakdown the dataset has been done and various adaptation strategies are defined, some limitations of the data (namely, lacking technology expenditure) delay the intensive analysis, such as the level of investment in technology adoption. Further, a longer time span could help to understand the sustainable pattern of adoption choices and continuity/discontinuity of technology adoption as well. Lines of future research can focus on these directions.

Author Contributions: Conceptualization (ideas, outline, concepts), Q.-T.N.; methodology, Q.-T.N.; software application, Q.-T.N.; resources (data collection), Q.-T.N.; data curation, Q.-T.N.; writing—original draft preparation, Q.-T.N.; writing - review and editing, N.-P.D., T.-D.N., and T.-H.T.T. All authors have read and agreed to the published version of the manuscript.

Funding: This research received no external funding.

Acknowledgments: The authors are grateful to the two anonymous reviewers whose comments have contributed to improving the quality of this paper.

Conflicts of Interest: The authors declare no conflict of interest.

\section{References}

1. OECD. Enhancing the Contributions of SMEs in a Global and Digitalised Economy. In Proceedings of the Meeting of the OECD Council at Ministerial Level, Paris, France, 7-8 June 2017; pp. 7-8.

2. Filipe, S.F.; Grammatikos, T.; Michala, D. Forecasting distress in European SME portfolios. J. Bank. Financ. 2016, 64, 112-135. [CrossRef]

3. De Kok, J.; Deijl, C.; Veldhuis-Van Essen, C. Is Small Still Beautiful? Literature Review of Recent Empirical Evidence on the Contribution of SMEs to Employment Creation. Available online: http://lup.lub.lu.se/record/ cfac576e-a5c4-4802-b5f3-7989d9bffd46 (accessed on 15 May 2020).

4. Luetkenhorst, W. Corporate social responsibility and the development agenda. Intereconomics 2004, 39, 157-166. [CrossRef]

5. Jamali, D.; Lund-Thomsen, P.; Jeppesen, S. SMEs and CSR in developing countries. Bus. Soc. 2017, 56, 11-22. [CrossRef]

6. UNIDO. Corporate Social Responsibility: Implications for Small and Medium Enterprises in Developing Countries. Available online: https://www.unido.org/sites/default/files/2008-07/CSR_-_Implications_for_ SMEs_in_Developing_Countries_0.pdf (accessed on 15 May 2020).

7. Tan, K.G.; Tan, K.Y. Foreign Direct Investment (FDI), Productivity Spillovers and the Role of Small and Medium Enterprises (SMEs) Financing: An Overview. J. Int. Commer. Econ. Policy (JICEP) 2014, 5, 1-5. [CrossRef]

8. Czarnitzki, D.; Delanote, J. Young Innovative Companies: The new high-growth firms? Ind. Corp. Chang. 2013, 22, 1315-1340. [CrossRef]

9. Schneider, C.; Veugelers, R. On young highly innovative companies: Why they matter and how (not) to policy support them. Ind. Corp. Chang. 2010, 19, 969-1007. [CrossRef]

10. Veugelers, R. The role of SMEs in innovation in the EU: A case for policy intervention? Rev. Bus. Econ. 2008, 53, 239-262.

11. Aghion, P.; Howitt, P. Growth with quality-improving innovations: An integrated framework. Handb. Econ. Growth 2005, 1, 67-110.

12. Ortega-Argilés, R.; Vivarelli, M.; Voigt, P. R\&D in SMEs: A paradox? Small Bus. Econ. 2009, 33, 3-11.

13. Rammer, C.; Czarnitzki, D.; Spielkamp, A. Innovation success of non-R\&D-performers: Substituting technology by management in SMEs. Small Bus. Econ. 2009, 33, 35-58.

14. Dahlander, L.; Gann, D.M. How open is innovation? Res. Policy 2010, 39, 699-709. [CrossRef] 
15. Spithoven, A.; Vanhaverbeke, W.; Roijakkers, N. Open innovation practices in SMEs and large enterprises. Small Bus. Econ. 2013, 41, 537-562. [CrossRef]

16. Máñez, J.A.; Rochina-Barrachina, M.E.; Sanchis-Llopis, A.; Sanchis-Llopis, J.A. The determinants of R\&D persistence in SMEs. Small Bus. Econ. 2015, 44, 505-528.

17. Audretsch, D.B.; Segarra, A.; Teruel, M. Why don't all young firms invest in R\&D? Small Bus. Econ. 2014, 43, 751-766.

18. Tingvall, P.G.; Poldahl, A. Determinants of firm R\&D: The role of relationship-specific interactions for R\&D spillovers. J. Ind. Compet. Trade 2012, 12, 395-411.

19. Chang, C.; Robin, S. Doing R\&D and/or importing technologies: The critical importance of firm size in Taiwan's manufacturing industries. Rev. Ind. Organ. 2006, 29, 253-278.

20. Brandt, L.; Zhu, S.C. Technology Adoption and Absorption: The Case of Shanghai Firms; University of Toronto: Toronto, ON, Canada, 2005.

21. Bartoloni, E.; Baussola, M. The determinants of technology adoption in Italian manufacturing industries. Rev. Ind. Organ. 2001, 19, 305-328. [CrossRef]

22. Glass, A.J.; Saggi, K. International technology transfer and the technology gap. J. Dev. Econ. 1998, 55, 369-398. [CrossRef]

23. Basant, R.; Fikkert, B. The effects of R\&D, foreign technology purchase, and domestic and international spillovers on productivity in Indian firms. Rev. Econ. Stat. 1996, 78, 187-199.

24. Wang, J.-Y.; Blomström, M. Foreign investment and technology transfer: A simple model. Eur. Econ. Rev. 1992, 36, 137-155. [CrossRef]

25. Newman, C.; Rand, J.; Talbot, T.; Tarp, F. Technology transfers, foreign investment and productivity spillovers. Eur. Econ. Rev. 2015, 76, 168-187. [CrossRef]

26. Zapkau, F.B.; Schwens, C.; Kabst, R. Foreign direct investments and domestic employment of German SMEs: The moderating effect of owner management. J. Small Bus. Manag. 2014, 52, 451-476. [CrossRef]

27. Caves, R.E. Multinational firms, competition, and productivity in host-country markets. Economica 1974, 41, 176-193. [CrossRef]

28. Rodriguez-Clare, A. Multinationals, linkages, and economic development. Am. Econ. Rev. 1996, 86, 852-873.

29. Markusen, J.R.; Venables, A.J. Foreign direct investment as a catalyst for industrial development. Eur. Econ. Rev. 1999, 43, 335-356. [CrossRef]

30. Blalock, G.; Gertler, P.J. Welfare gains from foreign direct investment through technology transfer to local suppliers. J. Int. Econ. 2008, 74, 402-421. [CrossRef]

31. Smarzynska Javorcik, B. Does Foreign Direct Investment Increase the Productivity of Domestic Firms? In Search of Spillovers Through Backward Linkages. Am. Econ. Rev. 2004, 94, 605-627. [CrossRef]

32. Kugler, M. Spillovers from foreign direct investment: Within or between industries? J. Dev. Econ. 2006, 80, 444-477. [CrossRef]

33. Smeets, R. Collecting the pieces of the FDI knowledge spillovers puzzle. World Bank Res. Obs. 2008, 23, 107-138. [CrossRef]

34. Giroud, A.; Jindra, B.; Marek, P. Heterogeneous FDI in transition economies-A novel approach to assess the developmental impact of backward linkages. World Dev. 2012, 40, 2206-2220. [CrossRef]

35. Dunne, T. Plant age and technology use in US manufacturing industries. Rand J. Econ. 1994, 488-499. [CrossRef]

36. Cohen, W.M.; Levin, R.C. Empirical studies of innovation and market structure. Handb. Ind. Organ. 1989, 2, 1059-1107.

37. Rose, N.L.; Joskow, P.L. The Diffusion of New Technologies: Evidence from the Electric Utility Industry; National Bureau of Economic Research: Cambridge, MA, USA, 1988.

38. Vishwasrao, S.; Bosshardt, W. Foreign ownership and technology adoption: Evidence from Indian firms. J. Dev. Econ. 2001, 65, 367-387. [CrossRef]

39. Cooke, P. A ground-up "Quaternary" innovation strategy for South Korea using entrepreneurial ecosystem platforms. J. Open Innov. Technol. Mark. Complex. 2017, 3, 10. [CrossRef]

40. Mansfield, E. Industrial Research and Technological Innovation: An Econometric Analysis; Yale University: Yale, CT, USA, 1968.

41. David, P.A. A Contribution to the Theory of Diffusion; Research Center in Economic Growth, Stanford University: Stanford, CA, USA, 1969. 
42. Davies, S. The Diffusion of Process Innovations; CUP Archive: Cambridge, UK, 1979.

43. Ireland, N.; Stoneman, P. Technological diffusion, expectations and welfare. Oxf. Econ. Papers 1986, 38, 283-304. [CrossRef]

44. Reinganum, J.F. The timing of innovation: Research, development, and diffusion. Handb. Ind. Organ. 1989, 1, 849-908.

45. Fudenberg, D.; Tirole, J. Preemption and rent equalization in the adoption of new technology. Rev. Econ. Stud. 1985, 52, 383-401. [CrossRef]

46. Faria, A.; Fenn, P.; Bruce, A. Determinants of adoption of flexible production technologies: Evidence from Portuguese manufacturing industry. Econ. Innov. New Technol. 2002, 11, 569-580. [CrossRef]

47. Arvanitis, S.; Hollenstein, $\mathrm{H}$. The determinants of the adoption of advanced manufacturing technology: An empirical analysis based on firm-level data for Swiss manufacturing. Econ. Innov. New Technol. 2001, 10, 377-414. [CrossRef]

48. Karshenas, M.; Stoneman, P.L. Rank, stock, order, and epidemic effects in the diffusion of new process technologies: An empirical model. RAND J. Econ. 1993, 24, 503-528. [CrossRef]

49. Kelley, M.R.; Helper, S. Firm size and capabilities, regional agglomeration, and the adoption of new technology. Econ. Innov. New Technol. 1999, 8, 79-103. [CrossRef]

50. Meyer, J. Workforce age and technology adoption in small and medium-sized service firms. Small Bus. Econ. 2011, 37, 305-324. [CrossRef]

51. Antonelli, C.; Gottardi, G. Localised Technological Change: The Interaction Between The Generation And The Diffusion Of New Technologies. Econ. Innov. New Technol. 1991, 1, 309-325. [CrossRef]

52. Karpaty, P.; Kneller, R. Demonstration or congestion? Export spillovers in Sweden. Rev. World Econ. 2011, 147, 109-130. [CrossRef]

53. Blomström, M.; Kokko, A.; Zejan, M. Host country competition, labor skills, and technology transfer by multinationals. Weltwirtschaftliches Archiv. 1994, 130, 521-533. [CrossRef]

54. Siddharthan, N.S.; Safarian, A.E. Transnational corporations, technology transfer and imports of capital goods: The recent Indian experience. Transnatl. Corp. 1997, 6, 31-50.

55. Pandit, B.L.; Siddharthan, N. Technological acquisition and investment: Lessons from recent Indian experience. J. Bus. Ventur. 1998, 13, 43-55. [CrossRef]

56. Kuo, H.-C.; Li, Y. A dynamic decision model of SMEs' FDI. Small Bus. Econ. 2003, 20, 219-231. [CrossRef]

57. CIEM; University of Copenhagen. Technology and Competitiveness in Vietnam: Evidence from a Survey in 2010; CIEM: Ha Noi, Vietnam, 2011.

58. CIEM; University of Copenhagen. Technology and Competitiveness in Vietnam: Evidence from a Survey in 2011; CIEM: Ha Noi, Vietnam, 2012.

59. CIEM; University of Copenhagen. Technology and Competitiveness in Vietnam: Evidence from a Survey in 2012; CIEM: Ha Noi, Vietnam, 2013.

60. Ngo, Q.-T.; Nguyen, C.T. Do export transitions differently affect firm productivity? Evidence across Vietnamese manufacturing sectors. Post-Communist Econ. 2019, 1-27. [CrossRef]

61. Anwar, S.; Nguyen, L.P. Is foreign direct investment productive? A case study of the regions of Vietnam. J. Bus. Res. 2014, 67, 1376-1387. [CrossRef]

62. Anwar, S.; Nguyen, L.P. Absorptive capacity, foreign direct investment-linked spillovers and economic growth in Vietnam. Asian Bus. Manag. 2010, 9, 553-570. [CrossRef]

63. Mundlak, Y. On the pooling of time series and cross section data. Econom. J. Econom. Soc. 1978, 46, 69-85. [CrossRef]

64. Chamberlain, G. Multivariate regression models for panel data. J. Econom. 1982, 18, 5-46. [CrossRef]

65. Abraham, F.; Konings, J.; Slootmaekers, V. FDI Spillovers, Firm Heterogeneity and Degree of Ownership: Evidence from Chinese Manufacturing; Unpublished Paper; Department of Economics, Catholic University of Leuven: Leuven, Belgium, November 2006.

66. Wang, Y.; Roijakkers, N.; Vanhaverbeke, W.; Chen, J. How Chinese firms employ open innovation to strengthen their innovative performance. Int. J. Technol. Manag. 2012, 59, 235-254. [CrossRef]

67. Scherer, F.M. Firm size, market structure, opportunity, and the output of patented inventions. Am. Econ. Rev. 1965, 55, 1097-1125. 
68. Kamien, M.I.; Schwartz, N.L. Market structure and innovation: A survey. J. Econ. Lit. 1975, 13, 1-37.

69. Katz, M.L.; Shapiro, C. R and D rivalry with licensing or imitation. Am. Econ. Rev. 1987, 77, 402-420.

70. Loury, G.C. Market structure and innovation. Q. J. Econ. 1979, 93, 395-410. [CrossRef]

(C) 2020 by the authors. Licensee MDPI, Basel, Switzerland. This article is an open access article distributed under the terms and conditions of the Creative Commons Attribution (CC BY) license (http://creativecommons.org/licenses/by/4.0/). 